\title{
Complementation of Aquatic Trade between China and ASEAN: GL Index and BL Index Analysis Based on the Belt and Road Initiative
}

\author{
Xiao-fei Luo', Yong-hui Han ${ }^{2}$, \\ ${ }^{1}$ Faculty of Logistics, Guangdong Mechanical and Electrical Technical College, Guangzhou, \\ Guangdong, China \\ ${ }^{2}$ GIIS, Guangdong University of Foreign Studies, Guangzhou, Guangdong, China
}

\begin{abstract}
Keywords: China-ASEAN; Aquatic Industry; Complementation; B\&R
Abstract. Since the Belt and Road Initiative was proposed by Xi Jinping, the ASEAN-China Free Trade Area has been increasingly upgrading. In this background, this article thoroughly analyses the complementation of the aquatic trade between China and ASEAN based on the HS classification, by calculating the Grubel-Lloyd Intra-Industry Trade Index, Bruelhart Marginal Intra-Industry Trade Index successively. The results show that the aquatic trade is mainly inter-industry trade and overall, the aquatic trade between China and ASEAN is more complementary than competitive and has great potential.
\end{abstract}

\section{Introduction}

The Land and Maritime Silk Road came into being from the Qing and Han Dynasties. It has experienced the prosperity of Tang and Song Dynasties and the changes in Ming and Qing Dynasties. Since then, the relation between China and the Southeast Asia countries has been enduring and their economy and trade cooperation has been vigorous. Since 2002, when the Framework Agreement on Comprehensive Economic Cooperation between China and ASEAN was signed, which marks the beginning of the construction of ACFTA, the intra area trade between China and ASEAN has achieved great leaps [1]. During 2002 to 2012, the trade volume between China and ASEAN has increased by 6.6 times, with an average annual growth rate of $22 \%$. The average annual exports grow by $24.07 \%$, and the average annual imports grow by $24.73 \%$. In 2012, bilateral trade volume between China and ASEAN exceeded $\$ 400$ billion.

As aquatic products are one of the world's most important agricultural products, aquaculture industry plays a vital role in China's food security strategy and the development of aquatic trade is conducive to its national economy. Owing to the geographical link, the bilateral aquatic trade between Southeast Asia countries and China has been enduring for centuries. In recent years, the aquatic trade volume between China and ASEAN increased rapidly. In 2002, it is only US\$309.31 million while in 2012 it rose to US $\$ 1754.19$ million by more than 5-fold increase and the trade surplus is also increasing year by year. Especially since the completion of ACFTA in 2010, as the tariffs on aquatic products between China and ASEAN are cut to zero, the growth of aquatic trade between the two areas has been accelerating accordingly. As reported by the China's Customs, China's export of aquatic products to ASEAN increased by nearly 66\% over the year 2011.

Under the construction of The Silk Road Economic Belt and the 21st-century Maritime Silk Road, the bilateral aquatic trade between China and ASEAN are now facing a historic opportunity. In view of this, this paper makes a detailed analysis on the complementarities between China and ASEAN in aquatic trade based on the HS classification, hoping to provide an empirical evidence to strengthen the aquatic trade cooperation between China and ASEAN. This paper will follow the customary ways on studying the complementarities of bilateral trade cooperation to study the aquatic trade between China and ASEAN. It will calculate the four empirical measure indexes including Grubel-Lloyd Intra-Industry Trade Index, Bruelhart Marginal Intra-Industry Trade Index, Thom \& McDowell Horizontal and Vertical IIT Index, to thoroughly analyze the complementarities of aquatic trade between China and ASEAN. As a matter of fact, the chosen indexes are widely to study the bilateral trade relations in recent years. For examples, CHENG Rong and CHENG Hui-fang (2011) [2] used the index system to study the bilateral trade cooperation between China and India; HOU Min (2011) [3] 
used the index system to study the agricultural products trade between ASEAN and Australia; NC Leitão (2012) [4] used the index system to study the trade among countries that have similar demand while ZHENG Si-ning (2013) [5] used the index system to study the aquatic trade between Fujian and Taiwan.

\section{Methods on Complementarity Analysis}

This paper makes a comprehensive analysis on the intra-industry trade status and its structural characteristics of bilateral aquatic trade between China and ASEAN from both static and dynamic viewpoints with the following Indexes.

\section{Grubel-Lloyd Intra-Industry Trade Index (G-L Index)}

G-L index is commonly used to measure changes in the level of intra industry trade, it is calculated as:

$$
G L_{i}=1-\left|X_{i}-M_{i}\right| /\left(X_{i}+M_{i}\right),
$$

weighted average reflects the overall intra-industry trade level as:

$$
G L T=\sum_{i=1}^{n} G L_{i} \times\left[\left(X_{i}+M_{i}\right) / \sum_{i}^{n}\left(X_{i}+M_{i}\right)\right],
$$

where $i$ is the products of category $i$. The $G L i$ ranges $(0,1)$ and takes 0.5 as a critical point. If the index value is higher, the inter-industry trade level will be higher, otherwise, the intra-industry trade level will be higher. Calculate the $G-L$ index of intra industry trade of aquatic products between China and ASEAN with the above formulas and the results are as illustrated in Table 2. Overall, the weighted average of the $G-L$ total index $G L T$ from 2002 to 2012 show that the aquatic trade between China and ASEAN is of prominently complementary with high level of inter-industry trade. Specifically, the categories of aquatic products (all are primary products) of high $G-L$ index value, which are characterized by high intra-industry level, are 0302 (fresh or chilled fish), 0303 (whole frozen fish), 0304(fish fillets, fish meat, mince except liver, roe), 0306 (Crustaceans), 0307 (molluscs), 1504(not chemically modified fish, marine mammal fat or oil) and 121220(Seaweeds and other algae). Among these, the categories of 0304, 0303 and 0307 are especially high. The $G-L$ indices of categories 0301 (Live fish), 0305 (Fish, cured, smoked, fish meal for human consumption) and 051191 (non-food fish, shellfish and crustaceans) fluctuate greatly with intra-industry and inter-industry trade situation frequently alternative. Other than that, inter-industry still dominates most of the other categories of aquatic trade between China and ASEAN, which shows a strong complementarity.

Table 2. G-L Index of Aquatic Intra-Industry Trade between China and ASEAN

\begin{tabular}{cccccccccccc}
\hline HS Code & $\mathbf{2 0 0 2}$ & $\mathbf{2 0 0 3}$ & $\mathbf{2 0 0 4}$ & $\mathbf{2 0 0 5}$ & $\mathbf{2 0 0 6}$ & $\mathbf{2 0 0 7}$ & $\mathbf{2 0 0 8}$ & $\mathbf{2 0 0 9}$ & $\mathbf{2 0 1 0}$ & $\mathbf{2 0 1 1}$ & $\mathbf{2 0 1 2}$ \\
\hline $\mathbf{0 3 0 1}$ & 0.138 & 0.686 & 0.758 & 0.277 & 0.173 & 0.083 & 0.075 & 0.114 & 0.113 & 0.120 & 0.050 \\
$\mathbf{0 3 0 2}$ & 0.523 & 0.494 & 0.397 & 0.255 & 0.244 & 0.563 & 0.667 & 0.719 & 0.522 & 0.445 & 0.113 \\
$\mathbf{0 3 0 3}$ & 0.900 & 0.966 & 0.907 & 0.952 & 0.817 & 0.890 & 0.914 & 0.646 & 0.410 & 0.309 & 0.243 \\
$\mathbf{0 3 0 4}$ & 0.719 & 0.982 & 0.833 & 0.895 & 0.623 & 0.631 & 0.781 & 0.589 & 0.728 & 0.506 & 0.835 \\
$\mathbf{0 3 0 5}$ & 0.111 & 0.066 & 0.219 & 0.197 & 0.216 & 0.131 & 0.091 & 0.411 & 0.912 & 0.966 & 0.692 \\
$\mathbf{0 3 0 6}$ & 0.803 & 0.533 & 0.646 & 0.587 & 0.207 & 0.075 & 0.116 & 0.785 & 0.890 & 0.911 & 0.959 \\
$\mathbf{0 3 0 7}$ & 0.883 & 0.919 & 0.932 & 0.991 & 0.996 & 0.906 & 0.831 & 0.775 & 0.525 & 0.302 & 0.360 \\
$\mathbf{0 5 0 8}$ & 0.051 & 0.072 & 0.040 & 0.129 & 0.152 & 0.184 & 0.114 & 0.137 & 0.025 & 0.018 & 0.016 \\
$\mathbf{1 5 0 4}$ & 0.801 & 0.543 & 0.070 & 0.374 & 0.594 & 0.323 & 0.237 & 0.700 & 0.351 & 0.445 & 0.410 \\
$\mathbf{1 6 0 4}$ & 0.188 & 0.200 & 0.236 & 0.149 & 0.158 & 0.367 & 0.096 & 0.140 & 0.137 & 0.168 & 0.154 \\
$\mathbf{1 6 0 5}$ & 0.064 & 0.053 & 0.019 & 0.004 & 0.006 & 0.021 & 0.022 & 0.108 & 0.037 & 0.022 & 0.016 \\
$\mathbf{7 1 0 1}$ & 0.508 & 0.118 & 0.021 & 0.036 & 0.013 & 0.174 & 0.107 & 0.169 & 0.084 & 0.307 & 0.147 \\
$\mathbf{0 5 1 1 9 1}$ & 0.150 & 0.142 & 0.876 & 0.513 & 0.756 & 0.146 & 0.058 & 0.060 & 0.468 & 0.144 & 0.052 \\
$\mathbf{1 2 1 2 2 0}$ & 0.500 & 0.438 & 0.356 & 0.347 & 0.288 & 0.451 & 0.300 & 0.328 & 0.351 & 0.366 & 0.000 \\
$\mathbf{1 3 0 2 3 1}$ & 0.132 & 0.116 & 0.106 & 0.233 & 0.222 & 0.080 & 0.000 & 0.000 & 0.000 & 0.002 & 0.000 \\
$\mathbf{2 3 0 1 2 0}$ & 0.743 & 0.729 & 0.231 & 0.068 & 0.103 & 0.050 & 0.169 & 0.085 & 0.017 & 0.015 & 0.000 \\
$\mathbf{2 8 0 1 2 0}$ & 0.000 & 0.078 & 0.000 & 0.000 & 0.000 & 0.928 & 0.391 & 0.000 & 0.160 & 0.010 & 0.115 \\
$\mathbf{3 9 1 3 1 0}$ & 0.001 & 0.058 & 0.031 & 0.125 & 0.183 & 0.187 & 0.378 & 0.379 & 0.540 & 0.000 & 0.000 \\
$G L T$ & 0.573 & 0.506 & 0.454 & 0.430 & 0.378 & 0.399 & 0.371 & 0.505 & 0.410 & 0.355 & 0.335 \\
\hline
\end{tabular}




\section{Bruelhart Marginal Intra-Industry Trade Index (BL Index)}

The $G-L$ index can only examine the change of intra industry trade. In order to explain the dynamic changes the aquatic intra-industry trade between China and ASEAN, this paper uses $B L$ index to measure the bilateral trade between China and ASEAN. The index is computed as:

Error! Reference source not found.,

where $B L_{i}$ is marginal intra-industry trade index , takes value of $0-1 ; \Delta X_{i}$ and $\Delta M_{i}$ is the export and import variation of aquatic products of category $i$ between two periods. In order to avoid distorting the real situation of the dynamic total index because of ignoring the offsetting of positive and negative variable values of the above categories of products, this paper uses the weighted average method from Oliveras and Terra (1997) [6]to calculate the marginal intra-industry trade index of the total aquatic trade between China and ASEAN. The index is:

$$
B L T=\sum_{i=1}^{n} B L_{i} \times\left(\left|\Delta X_{i}\right|+\left|\Delta M_{i}\right|\right) / \sum_{i=1}^{n}\left(\left|\Delta X_{i}\right|+\left|\Delta M_{i}\right|\right) \text { Error! Reference source not found.. }
$$

The results of $B L$ marginal intra-industry trade index and the overall marginal intra-industry trade index of aquatic trade between China and ASEAN are in Table 3.

Table 3. Aquatic Intra-Industry Trade Index between China and ASEAN

\begin{tabular}{ccccccccccc}
\hline HS CODE & $\mathbf{0 2 - ~ 0 3}$ & $\mathbf{0 3 - ~ 0 4}$ & $\mathbf{0 4 - ~ 0 5}$ & $\mathbf{0 5 - ~ 0 6}$ & $\mathbf{0 6 - 0 7}$ & $\mathbf{0 7 - ~ 0 8}$ & $\mathbf{0 8 - ~ 0 9}$ & $\mathbf{0 9 - 1 0}$ & $\mathbf{1 0 - 1 1}$ & $\mathbf{1 1 - ~ 1 2}$ \\
\hline $\mathbf{0 3 0 1}$ & 0.000 & 0.996 & 0.000 & 0.000 & 0.000 & 0.060 & 0.000 & 0.111 & 0.100 & 0.002 \\
$\mathbf{0 3 0 2}$ & 0.588 & 0.637 & 0.000 & 0.208 & 0.445 & 0.000 & 0.000 & 0.000 & 0.000 & 0.000 \\
$\mathbf{0 3 0 3}$ & 0.000 & 0.836 & 0.632 & 0.150 & 0.000 & 0.960 & 0.000 & 0.000 & 0.097 & 0.000 \\
$\mathbf{0 3 0 4}$ & 0.000 & 0.537 & 0.684 & 0.000 & 0.543 & 0.703 & 0.258 & 0.000 & 0.269 & 0.000 \\
$\mathbf{0 3 0 5}$ & 0.000 & 0.602 & 0.280 & 0.108 & 0.000 & 0.310 & 0.000 & 0.000 & 0.703 & 0.000 \\
$\mathbf{0 3 0 6}$ & 0.208 & 0.952 & 0.000 & 0.000 & 0.000 & 0.258 & 0.212 & 0.000 & 0.297 & 0.419 \\
$\mathbf{0 3 0 7}$ & 0.000 & 0.966 & 0.000 & 0.332 & 0.670 & 0.353 & 0.000 & 0.000 & 0.000 & 0.544 \\
$\mathbf{0 5 0 8}$ & 0.000 & 0.000 & 0.245 & 0.058 & 0.000 & 0.236 & 0.244 & 0.000 & 0.000 & 0.026 \\
$\mathbf{1 5 0 4}$ & 0.000 & 0.000 & 0.000 & 0.939 & 0.037 & 0.216 & 0.108 & 0.291 & 0.653 & 0.000 \\
$\mathbf{1 6 0 4}$ & 0.237 & 0.335 & 0.072 & 0.169 & 0.000 & 0.000 & 0.000 & 0.117 & 0.236 & 0.108 \\
$\mathbf{1 6 0 5}$ & 0.040 & 0.005 & 0.000 & 0.000 & 0.183 & 0.024 & 0.000 & 0.000 & 0.003 & 0.005 \\
$\mathbf{7 1 0 1}$ & 0.000 & 0.000 & 0.051 & 0.000 & 0.351 & 0.000 & 0.000 & 0.000 & 0.859 & 0.000 \\
$\mathbf{0 5 1 1 9 1}$ & 0.133 & 0.000 & 0.000 & 0.532 & 0.000 & 0.013 & 0.022 & 0.000 & 0.000 & 0.005 \\
$\mathbf{1 2 1 2 2 0}$ & 0.183 & 0.000 & 0.302 & 0.161 & 0.562 & 0.022 & 0.442 & 0.384 & 0.425 & 0.366 \\
$\mathbf{1 3 0 2 3 1}$ & 0.044 & 0.396 & 0.037 & 0.209 & 0.000 & 0.738 & 0.000 & 0.000 & 0.005 & 0.000 \\
$\mathbf{2 3 0 1 2 0}$ & 0.716 & 0.000 & 0.000 & 0.136 & 0.010 & 0.015 & 0.000 & 0.004 & 0.019 & 0.000 \\
$\mathbf{2 8 0 1 2 0}$ & 0.144 & 0.397 & 0.000 & 0.000 & 0.877 & 0.399 & 0.431 & 0.099 & 0.000 & 0.000 \\
$\mathbf{3 9 1 3 1 0}$ & 0.000 & 0.214 & 0.309 & 0.000 & 0.147 & 0.000 & 0.000 & 0.308 & 0.256 & 0.000 \\
BLT & 0.156 & 0.348 & 0.172 & 0.107 & 0.097 & 0.249 & 0.074 & 0.039 & 0.123 & 0.172 \\
\hline
\end{tabular}

In the changes of the marginal intra-industry trade index of aquatic products trade between China and ASEAN from 2002 to 2012 as shown in Table 3, there are only 24 in 190 items of index over the critical value 0.5 , which mainly focus on product 0304 (fish fillets, fish meat, mince except liver, roe), 0303 (whole frozen fish) and 0307 (molluscs). This situation is basically consistent with the results of G-L index estimation: The aquatic products trade between China and ASEAN is mainly based on the inter industry trade and shows high complementarities.

\section{Conclusions}

In recent year, the trade between China and ASEAN has developed with a positive momentum and their trade cooperation is growing with their increasing economic complementarity. Under the new situation of building The Belt and Road, China and the ASEAN countries are facing a historical opportunity to accelerate their economic and trade cooperation. It's an irresistible trend that China and ASEAN shall further deepen their trade cooperation to meet each other's needs, which will also do good to the peace and development in the two areas. This paper thoroughly analyses complementation of the bilateral trade on aquatic products between the two areas by calculating the Grubel-Lloyd 
Intra-Industry Trade Index, Bruelhart Marginal Intra-Industry Trade Index successively, and found the truth as follows: the aquatic trade between China and ASEAN is mainly inter-industry trade and seems to be strong complementary. We also found it is of very strong complementarity in some specific aquatic products which means the potential of bilateral aquatic trade between China and SEAN is still underestimated.

Based on such historical background, it seems particularly necessary know how to make advantage of resources endowment of the two areas and find a feasible way to develop their bilateral aquatic trade. This paper attempts to propose the following suggestions: Strengthen the cooperation in marine industry with ASEAN to develop the aquatic trade between China and ASEAN. President Xi delivered a strategy vision of jointly build a China-ASEAN community of common destiny to Indonesia's parliament to give the direction for the cooperation in marine industry between China and ASEAN. Therefore, it shall be with all dimension and high standards to deepen the aquaculture industry cooperation with ASEAN, including offshore interconnection, coordinated development of marine fishery resources, research cooperation on aquaculture industry, environmental protection on maritime operations, disaster prevention and reduction, etc. It will certainly develop the aquatic trade between China and ASEAN by strengthening the integration of aquatic products industry chain of the two areas by ways of promoting the complementary combination on harbors alignment, ports connectivity, information sharing, transportation and warehousing construction.

\section{Acknowledgements}

We acknowledges the support from the National Natural Science Foundation of China (71603060), the Ministry of education of Humanities and Social Science project (16YJC790023), the 2015 Philosophy and Social Science Planning Project of Guangdong, China(GD15YYJ01), the Soft Science Research Program of Guangdong, China (2016A070706006), the 2016 Philosophy and Social Science Development Planning Project of Guangzhou, China(2016GZYB04), the 2015 Young Creative Talents project from the Guangdong Department of Education, China(2015WQNCX029).

\section{References}

[1] He MY and Fang YN: Analysis of Competition and Complementation of Agricultural Products Trade between Guangdong and ASEAN. International Economiecs and Trade Research. 24 (2008), p. 31-35.

[2] Cheng R, Cheng HF: China-India Trade Relation: Competition or Complementary. Journal of International Trade. 348 (2011), p.85-94.

[3] Hou M: Study on Complementary Relations of Agricultural Product Trade between ASEAN and Australia-New Zealand: an Analysis Based on RTA and OBC. Journal of International Trade. 348 (2011), p.89-96.

[4] Leitão N C: US marginal intra-Industry trade and country characteristics. African Journal of Business Management, 6(5) (2012), p.1960-1966.

[5] Zheng SN: Research on the Rivalrousness and Complementarity of Aquatic Products between Fujian and Taiwan.International, Economiecs and Trade Research. 29(2013), p.103-112.

[6] Oliveras, J., \& Terra, I.: Marginal Intra-Industry Trade Index: The Period and Aggregation Choice. WeltwirtschaftlichesArchiv, 133 (1997), p.170-178. 